\title{
EDITORIAL
}

\section{Perspectives in medical education: signposts to the future in educating respiratory specialists}

\author{
P. Palange*, J. Busari" ${ }^{\#}$ A. Hare ${ }^{\uparrow}$, J.H. McKillop ${ }^{+}$, J-L.C. Noël ${ }^{\S}$, M.J. Rosen ${ }^{f}$, \\ A.K. Simonds ${ }^{\pi, * *}$ and R. Stevenson ${ }^{\# \#}$
}

"Prediction is very difficult, particularly about the future." Niels Bohr (1885-1962).

W e are living in an exciting period due to current innovations and developments in science. As we learn more about the human gene, we try to cluster disorders and diseases in order to have a positive effect on medicine [1]. The Institute for Systems Biology (Seattle, WAS, USA) have developed the P4 medicine (or Predictive, Preventive, Personalised and Participatory medicine), in a move from traditional reactive medicine to proactive medicine. In the future, will the doctor actively search for the patient to predict and prevent a disease rather than wait? Will personalised and participatory care be given to all patients? [2]. There is no doubt that public health demand and research advances are pushing medicine into an era of transformation [3].

Fast moving societal, economical and technological changes are also reshaping the medical profession in general. The mobility of both patients and doctors within the European Union has focused even greater attention on the competency of doctors and their ability to practice medicine. Technological changes have introduced new concepts and challenges in how medical education is conducted, both by instruction and assessment.

In this milieu of complex and ever-evolving healthcare systems, how does the physician develop? How does one set expectations, provide experiences and evaluate outcomes which are the basic actions for providing a comprehensive programme in developing the physician as a professional? [4].

These trends will particularly impact on the practice of respiratory medicine. Therefore, it is crucial that the profession keeps pace. This requires particular efforts on behalf of the medical education reforms that have become relevant. The European Respiratory Society (ERS) took the first step in taking on the challenge. The ERS School organised an educational research seminar on June 3 and 4, 2011 in Dublin, Ireland, where

\footnotetext{
*ERS Past School Chair and Dipartimento Medicina Clinica "La Sapienza" University, Rome, Italy.

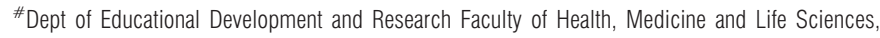
Maastricht, The Netherlands. "Academic Unit of Sleep and Breathing, Royal Brompton and Harefield NHS Foundation Trust, London, ${ }^{* *}$ ERS School Chair, ${ }^{+}$School of Medicine, University of Glasgow and ${ }^{\# \# A r d i n n i n g, ~ G l a s g o w, ~ U K . ~}{ }^{\mathrm{s} E u r o p e a n ~ R e s p i r a t o r y ~ S o c i e t y, ~ L a u s a n n e, ~ S w i t z e r l a n d . ~}{ }^{f}$ Global Education and Development, American College of Chest Physicians and Hofstra North Shore-LIJ School of Medicine, Hyde Park, NY, USA.
}

CORRESPONDENCE: J-L.C. Noël, European Respiratory Society, Avenue Ste-Luce 4, Lausanne, CH1003, Switzerland. E-mail: julie-lyn.noel@ersnet.org international experts in medical education and respiratory medicine attended, including colleagues from the American College of Chest Physicians (ACCP) and the American Thoracic Society. The seminar highlighted topics in medical education and regarded them as signposts for the future in educating respiratory specialists. The ERS intends to challenge current educational practices and seek out new methods in order to develop the competent and professional respiratory specialist. Perspectives on the evolution of medical education, instructional methods, simulation, continuing medical education (CME) and continuing professional development will now be discussed.

\section{EVOLUTION OF MEDICAL EDUCATION IN THE LAST 100 YRS}

Although the origins of western medical education can be traced from Greek and Roman times to the influence of Christian, Muslim and Jewish authorities in the early Middle Ages and then to 16th and 17th century figures such as Harvey, Vesalius and van Leeuwenhoek, major changes in medical education occurred almost exactly 100 yrs ago. This was the result of discoveries by 19th century researchers including Koch, Virchow, Pasteur, Semmelweiss, Lister, Mendel and Roentgen. Their findings resulted in the increasing application of scientific principles and knowledge in medical practice and the training of students and doctors.

In the USA and UK, this move was promoted by A. Flexner who published a report on North American medical education in 1910 and Canadian physician Sir W. Osler [5-7]. The key changes which they proposed were rapidly adopted in the USA, Canada and the UK and then in other countries as a framework for organising medical education. This has produced a robust model which remains influential today. However, in the last $30 \mathrm{yrs}$, challenges have arisen [8-10]. There is an ever increasing body of scientific and medical knowledge, both in the amount of material available on individual topics and the number of topics considered relevant. It has been observed that there is a tendency for individual topics to be seen as silos of knowledge rather than as being intimately linked and newly qualified doctors are well grounded in knowledge, but much less well equipped in practical and clinical skills and in essential interpersonal skills. There are the changing expectations of patients, the public and employers and changes in the pattern of healthcare delivery. The development of formal postgraduate education and training in all disciplines and the importance of multiprofessional and team work have challenged this model. 
In response, outcome-based frameworks and standards for undergraduate and/or postgraduate programmes such as Tomorrow's Doctors, CanMEDS, World Federation for Medical Education and the Scottish Doctor have been developed [11-14]. These programmes define essential outcomes required of graduates and provide frameworks which require achievement of particular competencies. Integrated curricula, which are often organ or system based, have come into existence. Integration can be horizontal (across disciplines which are traditionally taught in the same phase of the pre-clinical/clinical divide), vertical (across different curricular years, including across the preclinical/clinical divide) or both. Vertically integrated curricula are characterised by early clinical experience and by "science" content being delivered throughout the course. Not all students learn in the same way and it has been recognised that differing curricular models are necessary. It has also been emphasised that understanding and the ability to apply knowledge are essential. There is an increasing delivery of education in community settings rather than entirely in hospitals. Assessment methods that are robust and more appropriate are being developed. This includes deriving pass marks by standard setting procedures and blueprinting assessments against curricular outcomes. There is an increased recognition of curricular components relating to ethical and professional behaviour. Teaching and training are being professionalised.

This is an exciting time in medical education. Challenges continue in ensuring consistency in undergraduate and postgraduate training across different schools and countries.

\section{TOWARDS EFFECTIVE TEACHING METHODS FOR POSTGRADUATE RESPIRATORY MEDICINE}

The aim of teaching is to facilitate the process of learning and to ensure that those learning achieve the desired goals of any educational activity. Instructional methods are important for the learning process, as they are valuable tools for achieving the educational objectives.

Identifying the nature of learning outcomes is a key aspect of the instructional design process and, if not clearly identified, it is unlikely that worthwhile learning will occur. The aim of the instructional methods is to enable the learner to construct their own knowledge, build on existing knowledge bases, and find relevance and meaning in the process. Relevance and meaning are found by trying to make connections between the ideas that are being encountered and the real life practice of medicine.

It is important that the learning outcomes reflect the knowledge (cognitions), skills, attitudes and/or behaviours that should be learnt and which are relevant for clinical practice. These elements form the cornerstones of competency, which is the combination of these attributes with other resources, and the willingness to use them in the performance of a professional task [15]. Competencies arise from the areas of competence that can be identified in an analysis of the roles and functions of a doctor. Analysis of the areas of competency leads to identification of the specific competencies. Analysis of the competencies leads, in turn, to identification of the underpinning attributes, i.e. knowledge, skills and attitudes, and/or behaviour (table 1).

Therefore, intended learning outcomes are pre-defined "measurable outcomes" of the curriculum while instructional

\begin{tabular}{ll}
\hline TABLE 1 Desired professional roles of physicians \\
\hline Attributes & Competency \\
\hline Knowledge, i.e. cognitions & Scholar \\
Clinical skills, i.e. cognitive, technical & Medical expert \\
and psychomotor-perceptual skills & Scholar \\
& Medical expert \\
& Communicator \\
Attitudes and behaviour, i.e. cognitions & Manager \\
and affective skills & Professional \\
& Health advocate \\
& Communicator \\
& Collaborator \\
& Manager \\
\hline
\end{tabular}

methods are the "instruments" that are required to achieve these outcomes.

In light of the ongoing reform in postgraduate medical training, instructional methods are increasingly being seen as the vehicle for achieving the educational objectives in the clinical workplace. Instructional methods are needed in order to effectively transfer and apply new knowledge and skills in practice. The choice of which instructional method to use in educating trainees in the clinical workplace is determined primarily by the content of the curriculum and the context of the learning environment and later by the experience level of the trainee(s), the size of the group(s) and the variation within group(s) [16]. Instructional methods can involve the use of the learning environment itself, e.g. the patient's bedside, and/or a specific teaching strategy, e.g. case presentation. The most important learning environments in postgraduate medical training include the classroom or lecture hall, the inpatient setting, the ambulatory or out-patient clinical setting, and the remote learning environments. Furthermore, the setting where learning occurs within the different clinical environments can influence the choice of instructional methods. An overview of the learning settings within the different clinical environments, as well as the suitable instructional methods, is provided in table 2.

\section{SIMULATORS}

Medical simulation is defined as "a person, device or set of conditions which attempts to present (education and) evaluation of problems authentically. The student or trainee is required to respond to the problems they would under natural circumstances" [17]. A broad classification of simulation experiences is given in table 3 . These range from simple and high-fidelity mannequins to complex task-training models, e.g. for bronchoscopy, ultrasound and thoracoscopy, actor patients and simulated scenarios in which teams respond to a dynamic and evolving medical scenario in real time. Examples of the use of real-time scenarios in trauma team training were given at the ERS seminar [19].

The stimulus for the development of virtual and simulated techniques has come from many directions. A reduction in training time and reduced exposure to patients will clearly limit teaching opportunities. There is also a greater emphasis on improving the quality of medical skill training alongside 
TABLE 2 Overview of different learning environments and associated instructional methods

Learning environment

Setting

Wards

In-patient/hospital

Operating theatre

Grand rounds

Morning rounds

Patient handover rounds

Bedside teachings

Out-patient/

ambulatory clinic

Out-patient clinics

Remote/distance learning

Videoconferencing, e.g. Skype

Virtual learning environment

Classroom

Lecture rooms

Symposium

Workshop

Conferences

Suitable instructional methods

Strategy Size

\section{Lectures}

Direct observation of procedural skills

Case presentations

Peer-based learning

Active learning systems, e.g. simulators

1-min preceptor

Direct observation of consultation skills

Letters and feedback on letters/Sheffield

Assessment in Letters

Self-directed learning

Peer-based learning

E-learning/computer-assisted instruction

Letters and feedback on letters/Sheffield

Assessment in Letters

Lecture

Audience response systems

Team-based learning

Case methods/case-based discussions

Clinical demonstrations

Active learning systems conventional knowledge-based learning by lectures and tutorials. This is coupled with a societal and ethical overbearing. Understandably, patients do not want to be "practised on" by students new to a technique. From an ethical perspective, we owe it to the patients to perform practical techniques competently and to a high and reproducible standard [18]. A greater emphasis on safety, reducing healthcare errors and learning from experience is a mandatory part of our daily delivery of care in hospitals and the community. Simulation training in other professions and industries (such as the airline industry) is widely accepted. Simulation training in medical schools has advanced rapidly and is routine in some specialist areas such as resuscitation, surgery and anaesthetics. Indeed, the first simple resuscitation mannequins date back to the 1950s. Gradually these techniques are gaining traction in postgraduate medical education and for continuous medical education purposes. There is no reason why these approaches should not be subject to rigorous evaluation.

The apprenticeship model of medical training is centuries old and is based on the principles that knowledge is individually constructed by learners, is mediated by others (more senior clinicians), is most effective when activities are authentic and that knowledge construction is context specific [20]. It is informed by effective feedback, but in most clinical training programmes this acquisition of skills is reliant on opportunistic teaching (depending on the patients admitted/in the clinic etc.) and by the mentor's ability to customise learning to the student's needs.

\section{TABLE 3 Classification of simulator experiences}

Simulator Examples

\section{Low fidelity}

High fidelity

Computer-based models

Complex task trainers

Simulated scenarios
Simple resuscitation mannequins, tracheostomy models

Model limbs for i.v. cannula insertion

Responsive, programmable "sim-men" that simulate anatomy and changing physiology

Programmes presenting clinical scenarios to assess decision making

Virtual ventilators with ventilator setting "buttonology"

Virtual reality and tools combined to reproduce clinical experience, e.g. bronchoscopy and laparoscopy

Combination of simulated patients in real or simulated environment to train individuals/teams in complex clinical

situations, e.g. major trauma, resuscitation and critical incidents

Modified from [18] 
Simulator-based learning (SBL) does not, or should not, aim to replace apprenticeship training but should complement it. In particular, SBL attempts to focus on mastering a technique coupled with "deliberate practice". The latter concept incorporates careful definition of learning objectives, an appropriate level of difficulty, repetitive practice and informed feedback with error correction and reflection.

More recently, there have been several meta-analyses and systematic reviews [21-23] comparing conventional teaching with SBL.

ISSENBERG et al. [21] concluded that SBL was effective if the following criteria were met: 1) feedback was provided; 2) skills were practiced repetitively; 3) SBL was integrated into the overall curriculum; 4) the simulator complemented multiple learning strategies; 5) learners practice with increasing levels of difficulty; 6) clearly defined outcomes and benchmarks; and 8) individualised learning in a controlled environment.

In conclusion, SBL is eminently applicable to respiratory medicine and deserves wider use and evaluation. It has relevance to training in diverse areas such bronchoscopy, ultrasound, thoracoscopy, noninvasive ventilation and continuous positive pressure ventilation, and can aid the acquisition of communication skills. The ERS School, in partnership with national teams, is well placed to provide simulation courses and evaluate the results. Importantly, SBL has been shown to improve patient outcomes. As observed by VOZENILEK et al. [24], instead of "see one, do one, teach one" a more intelligent mantra should be "see one, simulate many, do one competently and teach everyone".

\section{IMPACT OF CME ON PHYSICIAN PERFORMANCE}

The ultimate goal of CME is to enhance the physician's ability to care for patients [25]. While we assume that CME promotes this goal, strong evidence of a link between education and improved physician practice and patient outcomes is lacking.

The 2009 ACCP evidence-based educational guidelines on the effectiveness of CME reported on the results of a search and systematic review of the literature with the goal of furthering the effectiveness of CME programmes [26]. The report indicated that the level of evidence of effectiveness of CME was generally of low quality because standardised $\mathrm{CME}$ approaches and CME research was lacking, making quantitative syntheses impossible. Nevertheless, recommendations were made to improve the effects of CME on knowledge, skills, practice performance and clinical outcomes. The common thread was the recommendation that multimedia CME interventions and exposures were preferred to single techniques and exposures. As for improving practice performance, both live and multiple media were recommended, and "print media should not be used alone to improve physician practice performance".

"Performance-improvement CME" (PI-CME) is a newer approach that includes a three-step process starting with a gap analysis based on assessment of the physician's current practice, with standardised evidence-based performance measures and feedback to compare performance to benchmarks. The second step is implementation of an intervention based on the practice's performance measures, and the third step re-evaluation of performance in practice [27]. PI-CME is now a requirement for maintenance of board certification in several US specialties. CME and instructional designers will be challenged to consider the application of multiple educational interventions in tandem with traditional performance improvement strategies, and research on the effectiveness of PI-CME to account for physician performance and patient outcomes.

\section{CME ACCREDITATION}

European CME accreditation at national levels is usually performed by a national accreditation authority (NAA) to which CME providers submit educational programmes (live events or e-learning) for approval. Each activity is individually examined to assure that there is a need for it, that its content is valid, that it will be delivered in an effective manner and that there is no evidence of commercial bias. Its approval by the NAA is often accompanied by a credit rating which usually reflects the amount of time the learner will devote to the activity. This process is known as activity accreditation.

CME for hospital doctors in North America is accredited differently. In the USA and Canada the NAAs accredit the providers rather than individual educational activities, i.e. provider accreditation. Although the number of activities is increasing, the number of providers is not and so there are economies of scale. In the USA, the accreditation council accredits national providers and also the State Medical Societies which in turn accredit their own local providers.

In Europe, there is discussion on the relative merits of the two systems. Activity accreditation is labour intensive when there are many activities and there are no economies of scale. Accreditation is based on prospective evaluation before the activity takes place and, therefore, does not include consideration of the learners' response to the education. Provider accreditation involves a detailed review of the provider's performance over recent years and includes consideration of the learners' feedback. Approval is graded; providers may be granted provisional accreditation for a short period if there are concerns about their performance, whereas a longer period of accreditation is awarded to providers whose performance is considered more satisfactory.

Dialogue between the European providers and the accreditation authorities will continue. The status quo of activity accreditation may persist or a hybrid model may be adopted in which major providers will apply for provider accreditation and minor or commercial providers will continue to apply for activity accreditation. If provider accreditation at some stage is considered desirable, it would be possible to develop a model similar to the US system. The European Accreditation Council for CME (EACCME) could accredit the major European providers (scientific societies) and accredit the activities of commercial European providers. It could also accredit the NAAs if their accreditation criteria met the standards of the EACCME. NAAs could then accredit their national providers in addition to carrying out activity accreditation for national commercial providers.

Whichever system Europe opts for, it must be remembered that the justification for accreditation of any kind is that it should result in improved provision and delivery of CME which in turn should contribute to better clinical care.

\section{CONCLUSIONS}

The perspectives offered by the authors, who are leading professionals in the field, intend to challenge current practices 
and give direction to educating future generations of respiratory specialists. With the current challenges and forces of change facing the profession, the ERS will respond with a renewal of its activities and educational initiatives keeping in mind these signposts. This, we hope, will support our members and wider respiratory medicine community and ultimately support the ERS mission of alleviating suffering from respiratory disease and promoting lung health.

\section{STATEMENT OF INTEREST}

A statement of interest for M.J. Rosen can be found at www.erj. ersjournals.com/site/misc/statements.xhtml

\section{REFERENCES}

1 Goh KI, Cusick ME, Valle D, et al. The human disease network. Proc Natl Acad Sci USA 2007; 104: 8685-8690.

2 Auffray C, Charron D, Hood L. Predictive, preventive personalized and participatory medicine: back to the future. Genome Med 2010; 2: 57.

3 Hood L, Friend S. Predictive, personalized, preventive, participatory (P4) cancer medicine. Nat Rev Clin Oncol 2011; 8: 184-187.

4 Stern DT, Papadakis M. The developing physician - becoming a professional. N Engl J Med 2006; 355: 1794-1799.

5 Flexner A, ed. Medical Education in the United States and Canada: A Report to the Carnegie Foundation for the Advancement of Teaching. Carnegie Foundation Bulletin No 4. Boston, The Merrymount Press, 1910.

6 Halperin EC, Perman JA, Wilson EA. Abraham Flexner of Kentucky, his report, Medical Education in the United States and Canada, and the historical questions raised by his report. Acad Med 2010; 85: 203-210.

7 Bean RB, Bean WB, eds. Sir William Osler: Aphorisms from His Bedside Teachings and Writings. New York, Henry Schuman, 1950.

8 General Medical Council. Tomorrow's Doctors 1993. Recommendations on Undergraduate Medical Education. London, General Medical Council, 1993.

9 Cooke M, Irby DM, O'Brien BC, et al. eds. Educating Physicians. Hoboken, Jossey-Bass, 2010.

10 Bleakely A, Bligh J, Browne J, eds. Medical Education for the Future: Identity, Power, and Location (Advances in Medical Education). Dordrecht, Springer, 2011.

11 General Medical Council. Tomorrow's Doctors 2009. Outcomes and Standards for Undergraduate Medical Education. London, General Medical Council, 2009.

12 Royal College of Physicians and Surgeons of Canada. The CanMEDS Framework. www.royalcollege.ca/public/resources/aboutcanmeds Date last accessed: January 16, 2012
13 World Federation for Medical Education. Global Standards for Quality Improvement of Medical Education. Copenhagen, WFME, 1997. www.wfme.org/standards/world-standards-programme

14 Scottish Dean's Medical Curriculum Group. The Scottish Doctor. www.scottishdoctor.org Date last accessed: January 16, 2012.

15 Gonczi A, Hager P, Athanasou J, eds. The Development of Competency-Based Assessment Strategies for the Professions. National Office of Overseas Skills Recognition Research Paper No. 8. Canberra, Australian Government Publishing Service, 1993.

16 Cooper D, Beswick W, Whelan G. Intensive bedside teaching of physical examination to medical undergraduates: evaluation including the effect of group size. Med Educ 1983; 17: 311-315.

17 McGaghie WC. Simulation in professional competence assessment: basic considerations. In: Tektan A, McGutre CH, McGaghie WC, eds. Innovative Simulations for Assessing Professional Competence: From Paper-and-Pencil to Virtual Reality. Chicago, Dept of Medical Education, University of Illinois, 1999; pp. $7-22$.

18 Ziv A, Wolpe PW, Small SD, et al. Simulation-based medical education: an ethical imperative. Acad Med 2003; 78: 783-788.

19 Cope A. Stimulation. www.ers-education.org/pages/default.aspx? $\mathrm{id}=335 \&$ idBrowse $=87754 \& d e t=1$ Date last updated: June 2011 .

20 Steketee C, Bower A. Augmenting the clinical apprenticeship model. AARE 2007; 1-14.

21 Issenberg SB, McGaghie WC, Petrusa ER, et al. Features and uses of hi-fidelity medical simulations that lead to effective learning: a BEME systematic review. Med Teach 2005; 27: 10-28.

22 McGaghie WC, Issenberg SB, Cohen ER, et al. Does simulationbased medical education with deliberate practice yield better results than traditional clinical education? A meta-analytic comparative review of the evidence. Acad Med 2011; 86: 706-711.

23 Okuda Y, Bryson EO, DeMaria S Jr, et al. The utility of simulation in medical education:what is the evidence? Mt Sinai J Med 2009; 76: 330-343.

24 Vozenilek J, Huff JS, Reznek M. See one, do one, teach one: advanced technology in medical education. Acad Emerg Med 2004; 11: 1149-1154.

25 American Council of Continuing Medical Education. About Us. www.accme.org/index.cfm/fa/about.home/About.cfm Date last accessed: October 8, 2011.

26 Moores LK, Dellert E, Baumann MH, et al. Executive summary: effectiveness of continuing medical education: American College of Chest Physicians Evidence-Based Educational Guidelines. Chest 2009; 135: Suppl. 3, 1s-4s.

27 Kahn N, Bagley B, Tyler S. Performance improvement CME: core of the new CME. CPPD Report. American Medical Association Continuing Medical Education. No. 22. 2007. www.ama-assn.org/ resources/doc/cme/cppd22.pdf 